\title{
IMPROVING STUDENT INTEREST IN ENGINEERING THROUGH QUALITY ENHANCEMENT PROJECTS: MECHANICAL TESTING OF BIOMATERIALS
}

\author{
Barry Hojjatie, Lauren Hale, Carlos Ponce, and Minh Tran \\ Engineering Studies Program, Valdosta State University, Valdosta GA, USA
}

\section{INTRODUCTION}

bhojjati@valdosta.edu

Valdosta State University (VSU) has developed a Quality Enhancement Program (QEP) that focuses on creating an environment to support active learning in classroom through discipline-based inquiry projects, undergraduate research, and project-based learning. Through a grant from the QEP, the VSU engineering students enrolled in the Directed Study course (ENGR 4950) have performed various designs and experiments to develop suitable mechanical tests and computational techniques for determination of the strength of dental porcelains.

Dental ceramic prostheses must be designed and constructed to withstand the various multidirectional forces of mastication for many years without premature wear or discomfort to the user. Mechanical strength of dental ceramic restorations such as dental crowns and bridges is an important factor that controls the clinical success of these restorations. Many of these restorations fail prematurely which result in discomfort and cost to the patients. Selection of suitable dental ceramic materials and firing procedures are based on various test methods performed in engineering research laboratories. However, most of these test methods are ineffective in proper screening and selection of these materials. The objectives of this study were as follows:

1. To test the hypothesis that the bi-axial (piston-on-three ball) flexure test reduces inconsistencies in the strength values of brittle dental ceramics when compared to the uni-axial three-point flexure test.

2. To analyze the effect of pre-firing drying time on the mean flexural strength values of brittle dental ceramics.

\section{METHODS}

Using molds provided by the University of Florida, VSU students fabricated many porcelain bar and disk samples for three-point flexure testing and bi-axial flexure testing, respectively (Fig. 1). All samples were prepared in accordance to the guidelines set by International Organization for Standardization (ISO) for the testing of dental ceramic materials. Duceragold gold-bonding opaque dental porcelain was used to make all samples.
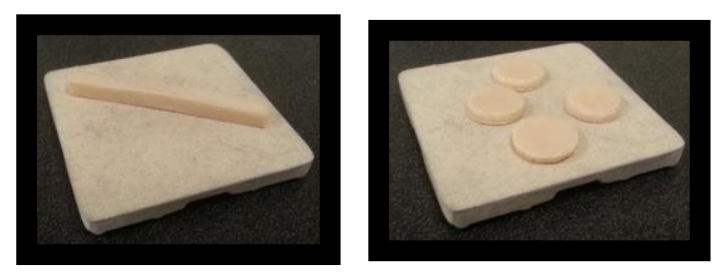

Fig. 1. Photographs of a porcelain bar (left) and some porcelain disks fabricated for mechanical testing.

\section{RESULTS}

Flexure strength of the bi-axial flexure samples was calculated by the expression developed by Wachtman, et al. [2] for the bi-axial flexure testing of ceramic substrates:

$$
\begin{aligned}
& \sigma=\frac{A P_{d}}{t^{2}} \\
& A=\left(\frac{3}{4 \pi}\right)\left[2(1+v) \ln \left(\frac{a}{r_{0}^{*}}\right)+\frac{(1-v)\left(2 a^{2}-r_{0}^{*}\right)}{2 b^{2}}+(1+v)\right] \\
& r_{0}^{*}=\left(1.6 r_{0}^{2}+t^{2}\right)^{\frac{1}{2}}-0.675 t
\end{aligned}
$$

Where:

$\sigma$, is the flexure strength (Mpa); $P_{d}$, is the load applied at failure $(N)$. $\mathrm{v}$, is Poisson's ratio $(\mathrm{v}=0.28)$; $\mathrm{a}$, is the radius of support circle $(\mathrm{mm})$. $\mathrm{b}$, is the radius of the sample $(\mathrm{mm})$; $t$, is the thickness of the sample $(\mathrm{mm})$. $r_{0}$, is the radius of the piston at the surface of contact (mm). $\mathrm{r}_{0} *$, is the equivalent radius defined by the expression above (mm). $\mathrm{r}_{0}{ }^{*}$, is the equivalent radius defined by the expression above (mm).

Shown in Fig. 2 is a comparison between the results obtained from the two flexure strength test methods.

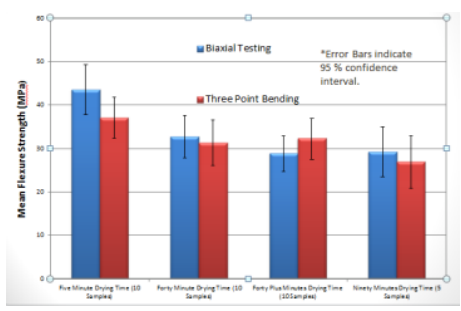

Fig. 2. Comparison between the mean flexure strength of dental porcelain obtained from the three-point bending and biaxial testing.

\section{DISCUSSION}

The mean coefficient of variability for the samples subjected to bi-axial testing was $22.6 \%$ which was slightly less that the corresponding value for those subjected to three-point flexure test $(24.2 \%)$. The calculated coefficients of variability from biaxial testing, for various groups ranging from 0.212 to 0.239 , were fairly constant and fell within the range of the coefficients of variability calculated by Ban, et al. [1], which ranged from 0.121 to 0.384 using a similar bi-axial test set up and various brittle dental materials.

\section{References}

[1] BAN, S.; HESEGAWA, J.; and ANUSAVICE, K.J., "Effects of Loading Conditions on Bi-axial Flexure of Dental Cements", Elsevier BV 8:100-1004, 1992.

[2] WACHTMAN, J.B., Jr.; CAPPS, W.; and MANDEL, J. "Biaxial Flexure Test of Ceramic Substrates", J. of Mat. Sci, 7:188-194, 1972. 